Instructions for authors, subscriptions and further details:

http://ijep.hipatiapress.com

\title{
Three Scales to Measure Burnout of Primary School Teachers: Empirical Evidence on their Adequacy
}

Maria Platsidou, Athena Daniilidou ${ }^{1}$

1) University of Macedonia

Date of publication: June $24^{\text {th }}, 2016$

Edition period: June 2016 - October 2016

To cite this article: Platsidou, M. \& Daniilidou, A. (2016). Three Scales to Measure Burnout of Primary School Teachers: Empirical Evidence on their Adequacy. International Journal of Educational Psychology, 5(2), 164-186. doi: 10.17583/ijep.2015.1810

To link this article: http://dx.doi.org/10.17583/ijep.2016.1810

\section{PLEASE SCROLL DOWN FOR ARTICLE}

The terms and conditions of use are related to the Open Journal System and to Creative Commons Attribution License (CC-BY). 


\section{Three Scales to Measure Burnout of Primary School Teachers: Empirical Evidence on their Adequacy}

Maria Platsidou

University of Macedonia
Athena Daniilidou

University of Macedonia

\section{Abstract}

This study aimed at comparing the psychometric properties of three measures of burnout administered in 320 Greek primary school teachers, namely the Maslach Burnout Inventory (Maslach and Jackson 1982), the Burnout Measure (Pines and Aronson 1988) and the Copenhagen Burnout Inventory (Kristensen et al. 2005). Confirmatory factor analysis tested a three-factor solution for each inventory, consistent to the respective theory. Results yielded a reasonably good model fit for the MBI, and merely acceptable model fit for the BM and the CBI. Overall the findings suggest that the MBI is more appropriate instrument for assessing teachers' burnout compared to the MB and the CBI, which presented not so well-defined inner structure and highly correlated subscales.

Keywords: burnout syndrome, teachers, Maslach Burnout Inventory, Burnout Measure, Copenhagen Burnout Inventory 


\section{Tres Escalas para Medir el} Burnout del Profesorado de Primaria: Evidencias

\section{Empíricas de su Adecuación}

Maria Platsidou

University of Macedonia
Athena Daniilidou

University of Macedonia

\section{Resumen}

El presente estudio se plantea con el objetivo de comparar las propiedades psicométricas de tres formas de medición del síndrome de burnout empleadas en 320 maestros de educación primaria griegos, concretamente, del Inventario del Síndrome de Burnout de Maslach (ISBM) (Maslach y Jackson, 1982), la Medición del Síndrome de Burnout (MSB) (Pines y Aronson, 1988) y el Inventario del Síndrome de Burnout de Copenhague (ISBC) (Kristensen et al., 2005). Mediante la aplicación de un análisis factorial confirmatorio, se examinó una solución, planteada de manera consistente con la teoría a la que se refería, de tres factores para cada inventario. Los resultados obtenidos indicaron una adecuación del modelo razonablemente buena para el ISBM y simplemente aceptable para el MSB y el ISBC. En general, los hallazgos señalan que el ISBM constituye un instrumento más adecuado para la evaluación del burnout de los docentes en comparación con el MSB y el ISBC, ya que estos presentan una estructura interna bastante indefinida, además de contar con subescalas altamente relacionadas entre ellas.

Palabras clave:

síndrome de burnout, profesorado, inventario del síndrome de Burnout de Maslach, medición del síndrome de burnout, inventario del síndrome de burnout de Copenhague. 
Tn work-related settings, burnout refers to the exhaustion of employees' capacity to maintain an intense involvement that has a meaningful Cimpact at work (Schaufeli, Leiter, \& Maslach, 2009) and it impairs (profoundly or not) their emotional, mental and physical state and manifestations. Teaching profession is considered one of the most stressful professions due to the frequent and intense interaction with students, parents and peers (Hakanen, Bakker \& Schaufeli, 2006). As a result, teachers are often driven to burnout. Ample research findings have shown that burnout of primary and secondary school teachers is high in most of the North European (Taris, Schaufeli, Schreurs \& Calje, 2000), North American (Mearns \& Cain, 2003), and Asian countries (Maslach, Schaufeli \& Leiter, 2001), as well as in Australia (Kyriakou, 1987). Rather lower levels of burnout are reported by teachers in most of the Mediterranean countries such as Cyprus (Kokkinos, 2006), Israel (Pines, 2004), Turkey (Demirel, Güler, Toktamis, Özdemir, \& Sezer, 2005) and Greece (Papastylianou, Kaila \& Polychronopoulos, 2009; Platsidou \&Agaliotis, 2008).Overall, research has not yet concluded whether differences in teachers' perceived burnout reflect varied levels of intense occupational stress or they imply that the meaning of burnout is not identical across countries and languages (Schaufeli et al., 2009).

Internationally, over $90 \%$ of the studies measuring teachers' burnout use the Maslach Burnout Measure (MBI, Maslach \&Jackson,1986), although other relevant research instruments have also been proposed (Kristensen, Borritz, Villadsen \& Christensen, 2005). Few studies have attempted to explore if preference of the MBI is warranted by its psychometric properties, comparing it to other scales, but they have not included recently designed scales. Therefore, this study was designed to compare measures of teachers' burnout obtained by three of the most widely used instruments, namely, the ones developed by Maslach and Jackson (1986), Pines and Aronson (1988), and Kristensen et al. (2005), respectively.

\section{Maslach Burnout Measure (MBI)}

The MBI is based on the Maslach and Jackson's (1986) model arguing that burnout arises as a result of prolonged work under pressure. The repeated failures to deal with tense and demanding situations in the workplace and the 
decline of resistance to work stress may lead a person to burnout (Maslach \& Schaufeli, 1993). According to this model, the syndrome of burnout is described by three dimensions which encompass different categories of symptoms: emotional exhaustion (feelings of being overextended and exhausted by work), depersonalization or cynicism (negative, uncaring attitudes toward recipients), and lack of personal accomplishment or reduced effectiveness (negative evaluation of performance and achievement in the job). Maslach and Jackson (1986) developed the MBI to assess the three aforementioned burnout dimensions of employees. Emotional exhaustion has been consistently viewed as the core, more stable and consistent component of the MBI (Schaufeli \& Enzmann, 1998; Shirom, 2005), which usually appears first and predicts the other two components in longitudinal studies (Maslach \& Schaufeli, 1993; Taris, Le Blanc, Schaufeli \& Schreurs, 2005).

The MBI has been undoubtedly the most widely used instrument for measuring burnout in a variety of occupations, cultures and work settings (Schutte, Toppinen, Kalimo, \& Schaufeli, 2000).Over the many years of research, ample evidence has been provided in support that the MBI is a reliable and valid measure of teacher burnout. Specifically, many factor analytic studies of teachers have reported three well-defined burnout factors representing emotional exhaustion, depersonalization, and reduced personal accomplishment with good internal consistency and test-retest reliability, as well as satisfactory convergent and discriminant validity (e.g., Demerouti, Bakker, Vardakou, \& Kantas, 2003; Kokkinos, 2006; Papastylianou et al., 2009; Kantas \& Vassilaki, 1997).Another asset of the MBI is that cut-off points are determined statistically, for instance, for "low", "average", and "high" scores of burnout, thus making test results easier to interpret (Maslach et al., 1996).

On the other hand, the MBI is criticized for being developed inductively and not stemming from a sound theoretical model (Shirom, 2005). As Kristensen et al. (2005, p. 193) note, the MBI and the Maslach definition of burnout "have become two sides of the same coin: Burnout is what the MBI measures, and the MBI measures what burnout is". In addition, they argue that depersonalisation is a coping strategy developed in a specific situation rather than a component of the burnout syndrome. As far as personal 
accomplishment is concerned, some studies have found that it develops largely independent from the other two burnout dimensions (Schutte et al., 2000); therefore, they claim it may not be part of the total concept of burnout. Moreover, Kristensen et al. (2005) critically note that the Maslach definition of burnout is applied exclusively to employees in the human service sector.

In prior studies, internal consistency of the MBI ranges from .70 to .90 (Maslach et al., 1996). Studies conducted in Greece and Cyprus have pointed satisfactory reliability indices for emotional exhaustion $(\alpha=.82$ to .85$)$ and personal accomplishment ( $\alpha=.72$ to .75$)$ and low to adequate reliability indices for depersonalization ( $\alpha=53$ to .63 ) (Kokkinos, 2006; Platsidou \& Agaliotis, 2008).

\section{Burnout Measure (BM)}

Pines and her colleagues defined burnout as a state of physical, emotional and mental exhaustion caused by long term exposure to emotionally demanding situations (Pines \& Aronson, 1988). "Physical exhaustion is characterized by low energy, chronic fatigue and weakness. Emotional exhaustion, the second component of burnout, involves primarily feelings of helplessness, hopelessness and entrapment. Mental exhaustion, the third component, is characterized by the development of negative attitudes towards one's self, work and life itself" (Pines \& Aronson, 1988, p.12). Tedium was proposed as an alternative term to describe burnout (Pines, Aronson \& Kafry, 1981). According to Pines, burnout is caused by the existential need of persons to give their life a meaning and, therefore, it is applicable to all life domains such as marital relationships (Pines, 1996) and aftermath of political conflicts (Pines, 1994). In the context of employment, in particular, Pines (2002) claims that when work fails to meet the person's need for a meaningful life, burnout is inevitable. She further emphasizes the role of work environment, while personality traits and motives contribute only in triggering and determining the severity of the syndrome. The most dedicated employees exhibit more severe forms of burnout.

Pines et al. (1981) developed the Burnout Measure (BM) scale to assess physical, mental and emotional exhaustion of people at work, which later 
became a very popular measure of burnout. Despite their multidimensional conception of burnout, Pines and Aronson (1988) do not place the three types of exhaustion into a theoretical framework and they do not provide explanations on how they develop, differentiate or interact over time (Enzmann, Schaufeli, Janssen, \& Rozeman, 1998). Consequently, although they classify the BM items into the three types of exhaustion described earlier, they compute one single burnout score. Subsequent research has produced ambivalent findings regarding the dimensionality of the BM: some studies have succeeded (Weisberg \& Sagie, 1999) while others have failed (Ray \& Miller, 1991; Schaufeli \& Van Dierendock, 1993) to support the hypothesized three-factor solution. At the same time, many researchers use the BM as a unidimensional or global construct (Corcoran, 1986; Pines \& Aronson, 1988). Finally, other studies have proposed a different pattern of dimensionality of the BM; for example, Schaufeli and van Dierendonck (1993) identified three correlated factors representing demoralization, exhaustion, and loss of motive; Shirom and Ezrachi (2003) argued that the $\mathrm{BM}$ structure is clearly multidimensional with imperfectly correlated constituent components. In relevant studies, internal consistency of the BM subscales ranged from .80 to .90 (Pines \& Aronson, 1981, 1988).

\section{Copenhagen Burnout Inventory (CBI)}

The Copenhagen Burnout Inventory (CBI) was proposed by Kristensen and his colleagues (2005) as a response to the harsh criticism leveled by themselves and other researchers to the model and, especially, the research instrument of Maslach and her partners. According to the theoretical considerations of the CBI, burnout may be conceptualized broadly as a state of exhaustion which is both general (personal burnout) and specific (work and client burnout) (Borritz \& Kristensen, 1999a, 1999b). Specifically, this research instrument assesses burnout in three subscales (Kristensen et al., 2005): personal burnout (the experience of physical and psychological fatigue and exhaustion), work-related burnout (refers to the person's own attribution of burnout symptoms to their work) and client-related burnout (the extent to which people attribute their exhaustion and fatigue to factors related to their "people work'). Personal burnout, the generic part of the 
CBI, may also occur among those who do not work such as young people, unemployed, early retired people, pensioners, and housewives. In the other two subscales, questions are formulated in such a way that they can be answered by employees of all professions. As Kristensen et al. (2005, p. 205) claim, "the three scales can be used in different domains (all persons, persons who work, and persons who do client-work)". Consequently, "in many concrete studies it would be meaningful to use only one or two of the scales".

As a recently developed scale, the CBI has still a long way to go to prove it is a valid and reliable scale for measuring burnout. So far, it has been translated into many languages and is being used in many cultures such as Japan (Odagiri, Shimomitsu, Ohya, \& Kristensen, 2004) and China (Lin \& Lin, 2013). Preliminary findings have shown that the CBI presents very good psychometric properties (e.g., high internal reliability, high convergent and divergent validity) in Danish (Kristensen et al., 2005) and Australian samples in various professions (Winnwood \& Winefield, 2004), as well as in paper-and-pencil and online administration (Campos, Zucoloto, Bonafe, Jordani \& Maroco, 2011). Its internal consistency and homogeneity, factorial validity and criterion-related validity were also found to be acceptable in a study of teachers in New Zealand (Milfont, Denny, Ameratunga, Robinson, \& Merry, 2008). Yet, many more studies having used the CBI in the last years do not report its psychometric properties (D' Souza, Egan \& Rees, 2011; Klein, Grosse Frie, Blum, \& Knesebeck, 2010).

\section{Aims and Hypotheses of the Present Study}

In this context, the study aimed at comparing three commonly used measures of teachers' burnout (MBI, BM and CBI), which are based on the three alternative theoretical models described earlier. More specifically, our first aim was to investigate the factorial validity and reliability of the three instruments administered in teachers. According to our hypothesis, for each of the three burnout inventories, a correlated three-factor model consistent to the original inventories will fit the data. Secondly, we investigated the interrelations of the different burnout measures to test for convergent validity. To support convergent validity, correlations between the MBI- 
emotional exhaustion scale, the BM and the CBI subscales are expected to be medium to high, since they all address a feeling of overtiredness focused on various domains (emotional, physical, mental) or sources (person, work, client). Depersonalization expresses a different aspect of burnout, so correlations with the above subscales are expected to be significant but lower and positive. Finally, reduced personal accomplishment indicates profound and all-out burnout, thus, it is expected to correlate moderately with the other burnout subscales.

\section{Method}

\section{Participants}

In this study, 320 primary school teachers working in public schools were tested, excluding teachers of specific teaching subjects such as music, sports, foreign languages etc. Data were collected from 49 state schools in urban and suburban areas of Greece. Of the participant teachers, 200 were female $(62.5 \%)$ and 120 male (37.5\%). The age of the sample ranged between 23 and 57 years, with a mean of 42.03 years $(S D=8.88)$. In relation to their marital status, 217 were married or in a permanent relationship (67.8\%), 101 were single $(31.6 \%)$ and 2 were widowed $(0.6 \%)$. As to their job characteristics, total teaching experience ranged from 1 to 34 years, with a mean of 16.23 years $(S D=8.53)$. One hundred and six teachers $(33.1 \%)$ had an MA or a $\mathrm{PhD}$ degree, while $214(66.9 \%)$ held a BA degree in Primary Education.

\section{Research Instruments}

Teachers' burnout was assessed using three of the most commonly used inventories of burnout. The first one (MBI) has been the measure of choice in most relevant studies of Greek teachers (e.g., Kantas \& Vassilaki, 1997; Papastylianou et al., 2009; Platsidou \& Agaliotis, 2008). The other two inventories had not been used before in the Greek context, to the best of our knowledge; so translation into Greek was done first with the help of a 
professor of English language and following the standard procedure for translation.

\section{Maslach Burnout Inventory (MBI)}

The Greek version of the Maslach Burnout Inventory (Maslach et al., 1996, translated by Kokkinos, 2006) was administered to the teachers. It contains 22 items that fall into three subscales: emotional exhaustion (9 items), depersonalization (5 items) and lack of a sense of personal accomplishment (8 items). Participants rated how frequently they experience these feelings on a 7-point scale, ranging from 0 (Never) to 6 (Daily).

\section{Burnout Measure (BM)}

The Burnout Measure was developed by Pines and Aronson (1988) to measure the three dimensions of burnout suggested by their theory: emotional exhaustion (7 items), physical exhaustion (7 items) and mental exhaustion ( 7 items). Teachers were asked to assess how frequently they experience the feelings described in the 21 items during the last 4-6 weeks using a 7-point scale, ranging from 0 (Never) to 6 (Daily). Scoring was reversed when necessary so that higher scores indicate elevated levels of burnout.

\section{Copenhagen Burnout Inventory (CBI)}

This inventory designed by Kristensen et al. (2005) consists of 19 items measuring personal burnout ( 6 items), work-related burnout ( 7 items) and client-related burnout (6 items). Participants rated how frequently they experience these feelings on a 5-point scale, ranging from 0 (Never) to 4 (Always). Scoring was reversed where necessary so that higher scores indicate higher levels of burnout. 


\section{Procedure}

Teachers were contacted either in person at their schools or via email by the second author and were asked to participate in the study voluntarily with no other incentive being offered. They were assured that their responses would be treated with confidentiality and strictly for the research purpose, and they would not be provided to superiors. After obtaining their informed consent to participating, the inventories were administered for completion. The usual time of completion was approximately $15 \mathrm{~min}$. Administration of the inventories took place from February to April 2014, that is, at the second half of the school year.

\section{Data Analysis}

Initially, a series of confirmatory factor analyses (using the maximum likelihood robust method of estimation) was performed to test the factorial validity of the three burnout instruments; analyses were run with the EQSWIN 6.1 program. To assess model fit we used well-established indices such as the x2-to-df ratio, CFI, SRMR, and RMSEA (Kline, 2005).In addition, reliability coefficients and means of the derived factors were computed. To examine convergent validity, correlations between the different burnout subscales were estimated.

\section{Results}

\section{Factorial Validity of the Three Burnout Instruments}

A correlated three-factor model was tested for each instrument in which the items loaded on their respective latent factor and the three latent factors were allowed to correlate. As Table 1 illustrates, factorial validity of the MBI was confirmed. Specifically, the ratio $\chi^{2} / \mathrm{df}=1.82, \mathrm{CFI}=.918, \mathrm{SRMR}=.065$ and RMSEA=.051 (CI90\% $.042-.059)$ indicated a reasonably good model fit. As expected, correlations between burnout dimensions were at medium to low levels and at the predicted direction. Reliability of the three subscales 
was satisfactory $(\alpha=.87$ for emotional exhaustion, $\alpha=.69$ for depersonalization and $\alpha=.88$ for personal accomplishment).

Table 1

The structure of the Maslach Burnout Inventory (standardized solution) in the test sample

Factors

\begin{tabular}{llllll}
\hline Items & ME & MP & MD & E & $\mathrm{R}^{2}$ \\
ME1 & .678 & & & .735 & .459 \\
ME2 & .734 & & & .679 & .539 \\
ME3 & .715 & & & .699 & 512 \\
ME4 & .849 & & & .528 & .721 \\
ME5 & .712 & & & .703 & .506 \\
ME6 & .357 & & & .934 & .127 \\
ME7 & .673 & & & .739 & .454 \\
ME8 & .762 & & & .648 & .580 \\
ME9 & .596 & & & .803 & .355 \\
MP10 & & .529 & & .848 & .280 \\
MP11 & & .741 & & .672 & .549 \\
MP12 & & .717 & & .698 & .513 \\
MP13 & & .704 & & .710 & .495 \\
MP14 & & .783 & & .622 & .614 \\
MP15 & .709 & & .705 & .503 \\
MP16 & & .689 & & .725 & .474 \\
MP17 & & .711 & & .703 & .505 \\
MD18 & & & .403 & .915 & .162 \\
MD19 & & & .845 & .535 & .714 \\
MD20 & & .745 & .667 & .555 \\
MD21 & & .426 & .905 & .181 \\
MD22 & & & .348 & .938 & .121 \\
\hline
\end{tabular}

\begin{tabular}{ll}
\hline Factor Correlations & \\
\hline F1 - F2 & -.206 \\
F2 - F3 & -.388 \\
F1 - F3 & .385 \\
\hline
\end{tabular}

Note $: \mathrm{ME}=$ Emotional Exhaustion; $\mathrm{MP}=$ Personal Accomplishment; $\mathrm{MD}=$ Depersonalization. All factors loadings, correlation and covariance indices are significant $(\mathrm{p}<.05)$. 
The hypothesized factorial validity of the BM was also confirmed (see Table 2) although, in this case, statistical indices demonstrated a barely acceptable model fit (Kline, 2005): $\chi^{2} / \mathrm{df}=3.6, \mathrm{CFI}=.902, \mathrm{SRMR}=.075$ and RMSEA=.079 (CI90\% .071-.086). The three burnout factors were moderately to highly correlated, especially the emotional with the mental exhaustion. Reliability indices of the BM subscales were very good: $\alpha=.88$ for emotional exhaustion, $\alpha=.83$ for mental exhaustion, and $\alpha=.92$ for physical exhaustion.

Table 2

The structure of the Burnout Measure (standardized solution) in the test sample

\begin{tabular}{|c|c|c|c|c|c|}
\hline Factors & & & & & \\
\hline Items & $\mathrm{PE}$ & $\mathrm{PM}$ & PP & $E$ & $\mathrm{R}^{2}$ \\
\hline PE1 & .700 & & & .714 & .490 \\
\hline PE2 & .816 & & & .578 & .666 \\
\hline PE3 & .781 & & & .625 & .610 \\
\hline PE4 & .569 & & & .823 & .323 \\
\hline PE5 & .671 & & & .741 & .451 \\
\hline PE6 & .752 & & & .660 & .565 \\
\hline PE7 & .663 & & & .748 & .440 \\
\hline PM8 & & .708 & & .706 & .502 \\
\hline PM9 & & .634 & & .773 & .402 \\
\hline PM10 & & .706 & & .708 & .499 \\
\hline PM11 & & .624 & & .781 & .389 \\
\hline PM12 & & .708 & & .707 & .501 \\
\hline PM13 & & .528 & & .849 & .279 \\
\hline PM14 & & .565 & & .825 & .319 \\
\hline PP15 & & & .796 & .605 & .634 \\
\hline PP16 & & & .868 & .496 & .754 \\
\hline PP17 & & & .886 & .463 & .785 \\
\hline PP18 & & & .737 & .676 & .543 \\
\hline PP19 & & & .867 & .499 & .751 \\
\hline PP20 & & & .866 & .500 & .750 \\
\hline PP21 & & & .369 & .929 & $\begin{array}{r}.136 \\
\text { nued) }\end{array}$ \\
\hline
\end{tabular}




\section{Factor}

Correlations

\begin{tabular}{ll}
\hline F1 - F2 & .865 \\
F2 - F3 & .512 \\
F1 - F3 & .617 \\
\hline
\end{tabular}

Note: $\mathrm{PE}=$ Emotional Exhaustion; PM = Mental Exhaustion; $\mathrm{PP}=$ Physical Exhaustion. All factors loadings and correlation and covariance indices are significant $(p<.05)$.

Similar to the above, the fit of the model testing factorial validity of the CBI was mediocre (Kline, 2005): $\chi^{2} / \mathrm{df}=2.92, \mathrm{CFI}=.898, \mathrm{SRMR}=.062$ and RMSEA $=.078(\mathrm{CI} 90 \%$.069-.086). Taken these reservations into consideration, we can tentatively assume that the hypothesized internal structure of the CBI was confirmed, as Table 3 presents. However, the three factors were highly or very highly correlated. Cronbach alphas indicated good reliability for the three CBI subscales $(\alpha=.90$ for personal burnout, $\alpha$ $=.84$ for work burnout and $\alpha=.78$ for client burnout).

Table 3

The structure of the Copenhagen Burnout Inventory (standardized solution) in the test sample

\begin{tabular}{llllll}
\hline Factors & & & & & \\
\hline Items & CP & CW & CS & E & $\mathrm{R}^{2}$ \\
CP1 & .798 & & & .603 & .636 \\
CP2 & .807 & & .591 & .651 \\
CP3 & .820 & & .572 & .673 \\
CP4 & .757 & & .653 & .573 \\
CP5 & .835 & & .550 & .698 \\
CP6 & .651 & & .759 & .423 \\
CW7 & & .686 & .728 & .470 \\
CW8 & & .843 & .538 & .710 \\
CW9 & & .590 & .807 & .348 \\
CW10 & & .753 & & .658 & .566 \\
& & & & (continued)
\end{tabular}




\begin{tabular}{|c|c|c|c|c|}
\hline Factors & & & & \\
\hline CW11 & .511 & & .860 & .261 \\
\hline CW12 & .618 & & .786 & .382 \\
\hline CW13 & .527 & & .850 & .278 \\
\hline CS14 & & .661 & .750 & .437 \\
\hline CS 15 & & .696 & .718 & .485 \\
\hline CS16 & & 609 & .793 & .371 \\
\hline CS17 & & .479 & .878 & .229 \\
\hline CS18 & & .660 & .751 & .436 \\
\hline CS19 & & .580 & .815 & .336 \\
\hline
\end{tabular}

Factor

Correlations

\begin{tabular}{ll}
\hline F1 - F2 & .904 \\
F2 - F3 & .796 \\
F1 - F3 & .706 \\
\hline
\end{tabular}

Note: $\mathrm{CP}=$ Personal Burnout; $\mathrm{CW}=$ Work-Related Burnout; $\mathrm{CS}=$ StudentRelated Burnout. All factors loadings and correlation and covariance indices are significant $(p<.05)$.

\section{Correlations among the Three Burnout Inventories}

Subsequently, correlation matrix of the different burnout measures was obtained. Inspection of Table 4 largely confirms our hypothesis. In general, the MBI-emotional exhaustion and the BM and the CBI subscales were moderately to highly correlated. Depersonalization had low bar significant correlations with the other burnout measures, but its correlation with the BM-physical exhaustion was not significant. Finally, personal accomplishment correlated negatively and moderately low with the BM and the MBI measures, with all correlations being significant. Overall, the mean of the CBI subscales presented higher correlations with both the mean of the MBI $(r=.683, \mathrm{p}<.001)$ and the mean of the BM subscales $(r=.706, \mathrm{p}<$ $.001)$ than the correlations between the last two $(r=.545, \mathrm{p}<.001)$. The differences between these correlations were found significant, $Z=-4.32, p<$ .001 and $Z=-3.34, p<.001$, respectively). 
Table 4:

Correlation matrix of the burnout subscales.

\begin{tabular}{|c|c|c|c|c|c|c|c|c|}
\hline & 1 & 2 & 3 & 4 & 5 & 6 & 7 & 8 \\
\hline \multicolumn{9}{|l|}{ MBI } \\
\hline \multirow{2}{*}{\multicolumn{9}{|c|}{$\begin{array}{l}\text { 1. Emot. } \\
\text { exhaust. }\end{array}$}} \\
\hline & & & & & & & & \\
\hline 2. Pers. & - & & & & & & & \\
\hline accompl. & $.197^{* *}$ & & & & & & & \\
\hline 3. & $310^{* *}$ & - & & & & & & \\
\hline Depersonaliz. & .310 & $.388^{* *}$ & & & & & & \\
\hline \multicolumn{9}{|l|}{$\mathrm{BM}$} \\
\hline $\begin{array}{l}\text { 4. Emot. } \\
\text { exhaust. }\end{array}$ & $.552^{* *}$ & $.235^{* *}$ & $.215^{* *}$ & & & & & \\
\hline $\begin{array}{l}\text { 5. Mental } \\
\text { exhaust. }\end{array}$ & $.515^{* *}$ & $.291^{* *}$ & $.227^{* *}$ & $.711^{* *}$ & & & & \\
\hline $\begin{array}{l}\text { 6. Physical } \\
\text { exhaust. }\end{array}$ & $.610^{* *}$ & $.143^{* \ldots}$ & $.095 .$. & $.638^{* *}$ & $.574^{* *}$ & & & \\
\hline \multicolumn{9}{|l|}{ CBI } \\
\hline $\begin{array}{l}\text { 7. Personal } \\
\text { burnout }\end{array}$ & $.684^{* *}$ & $.256^{* *}$ & $.191^{* *}$ & $.686^{* *}$ & $.567^{* *}$ & $.748^{* *}$ & & \\
\hline $\begin{array}{l}\text { 8. Work } \\
\text { burnout }\end{array}$ & $.728^{* *}$ & $.363^{* * *}$ & $.273^{* *}$ & $.562^{* *}$ & $.547^{* *}$ & $.627^{* *}$ & $.776^{* *}$ & \\
\hline $\begin{array}{l}\text { 9. Client } \\
\text { burnout }\end{array}$ & $.559^{* *}$ & $.360^{* * *}$ & $.320^{* *}$ & $.409^{* *}$ & $.358^{* *}$ & $.390^{* *}$ & $.587^{* *}$ & $.728^{* *}$ \\
\hline
\end{tabular}

\section{Discussion}

In this study, three commonly used measures of burnout were administered to Greek primary school teachers with the intention of comparing their psychometric properties. It is noted that the MBI has been widely used in Greek samples so far, but the BM and the CBI were used for the first time, so their factor structure was tested first. 


\section{Factorial Validity of the Three Burnout Inventories}

Confirmatory factor analysis of the hypothesized three-factor structure yielded a reasonably good model fit for the MBI, and merely acceptable model fit for the BM and the CBI. More specifically, the Greek version of the MBI was found to assess the three dimensions of teachers' burnout as predicted by the theory and their internal structure matched the original MBI (Maslach \& Jackson, 1986; Maslach et al., 1996). Reliability of the three subscales was satisfactory. This finding is consistently confirmed in other studies; in particular, invariant factorial validity and good reliability of the MBI have been noticed in most of the international (Boles et al., 2000; Byrne, 1991) and the Greek studies of teachers (Papastylianou et al., 2009; Platsidou \& Agaliotis, 2008), or other professionals (e.g., managers, clerks, foremen technicians, Schutte et al., 2000). It is interesting to note that factorial structure of the MBI, as well as the CBI, was invariant between paper-and-pencil and online administration and reliability was good in both formats (Campos et al., 2011). Against this backdrop, it can be easily comprehended why MBI has become so popular among researchers in so many countries, in spite of the criticism is has received (Kristensen et al., 2005; Shirom, 2005).

For the BM, confirmatory factor analysis revealed that the model of three subscales proposed by Pines and Aronson (1988, physical, emotional and mental exhaustion) adequately fits the data and the internal consistency of the three subscales was very good. Prior findings are inconclusive regarding the latent structure of the BM. Some studies (as reviewed by Enzmann et al., 1998), considered the BM a unidimensional scale, while in other studies a three-factor structure was identified, yet not corresponding to the dimensionality originally proposed. Although merely acceptable, the model fit of the present study confirmed the three subscales of the original BM. This alone is an important finding, given that no prior study has confirmed the proposed model in teacher samples. However, the high correlations between the three latent factors indicate the possibility of a general, higher order factor; this may support the argument that the BM captures a particular aspect of burnout related to fatigue and tiredness (Enzmann et al., 1998; Shirom \& Ezrachi, 2003). 
Finally, the factorial structure of the CBI was tested. Kristensen et al. (2005) provided empirical support of the reliability and validity of the CBI and showed it was adapted to different professional occupations, but they argued it should also be tested in different cultures. In the present study, the CBI is administered for the first time in Greek teachers. A three-factor model was tested, in which the CBI items load on their respective latent factor (personal, work and client burnout). This model was found to have a mediocre fit to the data. Internal consistency of the three latent factors was very good, however they were found to be highly correlated. High correlations between these factors were also found in prior studies, thus bringing into question whether the CBI subscales possess adequate discriminant validity, whether a general, higher order burnout factor is possible, or whether calculation of one single burnout score from the CBI is more justified rather than the three subscales(Milfont et al., 2008; Winwood \& Winefield, 2004).

\section{Relations among Burnout Measures}

In the next step, correlations among all burnout measures were estimated. The MBI-emotional exhaustion scale, the BM and the CBI subscales were found to be medium to highly intercorrelated. This finding supports convergent validity of the above burnout measures as it confirms that they all address a feeling of emotional, physical, or mental overtiredness related to the person, work, or client domain. As predicted, reduced personal accomplishment and depersonalization had, respectively, moderately low and low correlations with the BM and the CBI subscales. Correlations were significant and to the predicted direction, except for the correlation of depersonalization with physical exhaustion which was not significant.

Based on the above, it can be assumed that the MBI subscales actually assess different aspects of burnout, as described by the theoretical model (Maslach \& Jackson, 1986). On the other hand, the BM and the CBI subscales seem to assess quite similar manifestations or experiences of burnout and therefore the extraction of a single score for each inventory would be more justified rather than having a three-subscale solution. In agreement to the above, prior studies have reported that the discriminant 
validity of the BM is weak and concluded that the BM is not suitable for the measurement of burnout as a distinct phenomenon or for differentiating burnout from the related but distinct affective states of anxiety. Instead, they suggest it may be adequate as a general measure of psychological distress (Enzmann et al., 1998; Shirom \& Ezrachi, 2003; Schaufeli \& Van Dierendonck, 1993).

Likewise, earlier findings regarding the CBI have shown considerable dependency between the three burnout scales as they were highly intercorrelated (Milfont et al., 2008). Kristensen et al., (2005) notice that correlations between the three CBI scales varied considerably across different workplaces and, in general, are lower in other professions. Apparently, findings from the present study confirm that these correlations are fairly high in the teaching profession.

In conclusion, combined with the results of confirmation factor analysis discussed earlier, it appears that the MBI is more appropriate instrument for assessing teachers' burnout compared to the BM and the CBI, which presented not so well-defined inner structure and highly correlated subscales. On the other hand, earlier research has shown that the MBI and the CBI indicated substantial similarity in the overall proportion of respondents identified as manifesting high burnout (Winwood \& Winefield, 2004), which implies that the two measures of burnout converge. Evidently, more research is needed in the future to test the adequacy of the three-subscales of the BM and the CBI to fit data obtained by teachers in Greece as well as in other countries; many more findings need to be accumulated before the MBI is dethroned as the most preferred inventory for measuring teachers' burnout.

\section{Conclusions and Limitations}

In a nutshell, the present study confirmed the factorial structure of the MBI as proposed by its designers in our sample of Greek primary school teachers. In parallel, factorial structure of the BM and the CBI was also confirmed, although these models fitted adequately to the data. Furthermore, it showed that the MBI assesses different aspects of the burnout phenomenon, while in the other two measures subscale scores were fairly intercorrelated indicating that they might assess burnout as a more unified phenomenon. Based on the 
above, one could be advised to use the MBI if she wants to check differentiated aspects of teachers' burnout, or prefer the BM or the CBI if she seek to obtained a more unified measurement of burnout and with no need to reverse any scores.

The present study had certain limitations. Specifically, results do not apply to all teachers in the educational hierarchy and are likely to have been changing as a result of the financial situation of the country and the ongoing educational reforms that are causing stress and insecurity to all employees. Moreover, a measure of occupational stress could be used as a criterion variable to get a more comprehensive testing of the discriminant validity of the burnout measures in relation to familiar stress reactions.

\section{References}

Boles, J. S., Dean, D. H., Ricks, J. M., Short, J. C., \& Wang G. (2000). The dimensionality of the Maslach Burnout Inventory across small business owners and educators. Journal of Vocational Behavior, 56, 12-34. doi:10.1177/1094428104268027

Borritz, M., \& Kristensen, T. (1999a). Copenhagen Burnout Inventory (1st Ed.). Copenhagen, Denmark: National Institute of Occupational Health.

Borritz, M., \& Kristensen, T. (1999b). PUMA (Study on Personal Burnout, Work Burnout and Client Burnout). Copenhagen, Denmark: National Institute of Occupational Health.

Byrne, B. M. (1991). Burnout: Investigating the impact of background variables for elementary, intermediate, secondary, and university educators. Teaching and Teacher Education, 7, 197-209. doi: 10.1007/s11205-009-9533-7

Campos, J. A. D. B., Zucoloto, M. L., Bonafé, F. S. S., Jordani, P. C., \& Marôco, J. (2011). Reliability and validity of self reported burnout in college students: A cross randomized comparison of pencil-and-paper vs. online administration. Computers in Human Behavior, 27(5), 1875-1883. doi: 10.1590/S1807-25772013000500002 
Corcoran S. M. (1986). Planning by expert and novice nurses in cases of varying complexity. Research in Nursing and Health, 9, 155-162. doi: 10.1002/nur.4770090211

Demerouti, E., Bakker, A. B., Vardakou, I., \& Kantas, A. (2003). The convergent validity of two burnout Instruments: A multitrait multimethod analysis. European Journal of Psychological Assessment, 18, 296-307. doi: 10.1027//1015-5759.19.1.12

Demirel, Y., Guler, N., Toktamis, A., Ozdemir, D. \& Sezer, R.E. (2005) Burnout among High School Teachers in Turkey. Middle East Journal of Family Medicine, 3(3), 33-36.

D'Souza, F., Egan, S. J., \& Rees, C. S. (2011). The relationship between perfectionism, stress and burnout in clinical psychologists. Behavior Change, 28, 17-28. doi: 10.1375/bech.28.1.17

Enzmann, D., Schaufeli, W. B., Janssen, P., \& Rozeman, A. (1998).

Dimensionality and validity of the Burnout Measure. Journal of Occupational and Organizational Psychology, 71, 331-351.

doi: 10.1111/j.2044-8325.1998.tb00680.x

Hakanen, J., Bakker, A.B., \& Schaufeli, W.B. (2006). Burnout and work engagement among teachers. The Journal of School Psychology, 43, 495-513. doi:10.1016/j.jsp.2005.11.001

Kantas, A., \&Vassilaki, E. (1997). Burnout in Greek teachers: Main findings and validity of the Maslach Burnout Inventory. Work and Stress, 11, 94-100. doi:10.1080/02678379708256826

Klein, J., Grosse Frie, K., Blum, K., \& Knesebeck, O. v. d. (2010) Burnout and perceived quality of care among German clinicians in surgery. International Journal for Quality in Health Care, 22, 525-530. doi: 10.1093/intqhc/mzq056.

Kline, R. B. (2005). Principles and Practice of Structural Equation Modeling (2nd ed.). New York: Guilford Press.

Kokkinos, C. M. (2006). Factor structure and psychometric properties of the Maslach Burnout Inventory-Educators Survey among elementary and secondary teachers in Cyprus. Stress and Health, 22, 25-33. doi: 10.1002/smi.1079

Kristensen, T. S., Borritz, M., Villadsen, E., \& Christensen, K. B. (2005). The Copenhagen Burnout Inventory: a new tool for the assessment of 
burnout. Work \& Stress, 19, 192-207. doi:

10.1080/02678370500297720

Kyriacou, C. (1987). Teacher stress and burnout: An international review.

Educational Research, 29, 146-152. doi: 10.1080/0013188870290207

Lin, L. P. \& Lin, J. D. (2013). Job burnout amongst the institutional caregivers working with individuals with intellectual and developmental disabilities: Utilization of the Chinese version of the Copenhagen Burnout Inventory survey. Research in Autism Spectrum Disorders, 7, 777-784. doi: 10.1016/j.rasd.2013.03.004

Maslach, C. \& Jackson, S. E. (1986). Maslach Burnout Inventory Manual (2nd edition). Palo Alto: Consulting Psychologists Press.

Maslach, C. \& Schaufeli, W. B. (1993). Historical and conceptual development of burnout. In W. B. Schaufeli, C. Maslach \& T. Marek (Eds.). Professional Burnout: Recent Developments in Theory and Research. Washington: Taylor and Francis.

Maslach, C., Jackson, S.E., \& Leiter, M.P. (1996). Maslach Burnout Inventory Manual (3rd edn.). Palo Alto, CA: Consulting Psychologists Press.

Maslach, C., Schaufeli, W. B., \& Leiter, M. P. (2001). Job burnout. Annual Review of Psychology, 52, 397-422. doi:

10.1146/annurev.psych.52.1.397

Mearns, J., \& Cain, J. E. (2003). Relationships between teachers' occupational stress and their burnout and distress: Roles of coping and negative mood regulation expectancies. Anxiety, Stress, and Coping, 16, 71-82. doi: 10.1080/1061580021000057040

Milfont, T. L., Denny, S., Ameratunga, S., Robinson, E., Merry, S. (2008). Burnout and wellbeing: testing the Copenhagen Burnout Inventory in New Zealand teachers. Social Indicators Research, 89, 169-177. doi: 10.1007/s11205-007-9229-9.

Odagiri, Y., Shimomitsu, T., Ohya, Y., \& Kristensen, T. S. (2004).

Overcommitment and high effort are strongly associated with burnout among Japanese nurses. International Journal of Behavioral Medicine, 11(Suppl.), 214.

Papastylianou, A., Kaila, M., \& Polychronopoulos, M. (2009). Teachers' Burnout, Depression, Role Ambiguity and Conflict. Social 
Psychology of Education, 12, 295-314. doi:10.1007/s11218-008-90867

Pines, A. (1994). The Palestinian Intifiada and Israelis' burnout. Journal of Cross-cultural Psychology, 25, 438-451.

doi: $10.1177 / 0022022194254001$

Pines, A. M. (1996). Couple Burnout. New York: Routledge

Pines, A. M. (2002). Teacher burnout: A psychodynamic existential perspective. Teachers and Teaching: Theory and Practice, 8, 121-140. doi: 10.1037/0033-3204.39.1.103

Pines, A. M. (2004). Why Are Israelis Less Burned Out? European Psychologist, 9(2), 69-77. doi: 10.1027/1016-9040.9.2.69

Pines, A. M., Aronson, E., \& Kafry, D. (1981). Burnout: From Tedium to Personal Growth. New York: Free Press.

Pines, A. M., \& Aronson, E. (1988). Career Burnout: Causes and cures. New York: The Free Press.

Platsidou, M., \& Agaliotis, I. (2008). Burnout, job satisfaction and instructional assignment related sources of stress in Greek special education teachers. International Journal of Disability, Development and Education, 55, 61-76. doi: 10.1080/10349120701654613

Ray, E. B., \& Miller, K. I. (1991). The influence of communication structure and social support on job stress and burnout. Management Communication Quarterly, 4, 506-527. doi: 10.1177/0893318991004004005

Schaufeli, W. B \& Dierendock., V. D., (1993). The construct validity of two burnout measures. Journal of Organizational Behaviour, 14, 631-637. doi: 10.1002/job.4030140703

Schaufeli, W. B., \& Enzmann, D. (1998). The Burnout Campanion to Study and Practice: A Critical Analysis. London: Taylor and Francis.

Schaufeli, W. B., Leiter, M. P., \& Maslach, C. (2009). Burnout: 35 years of research and practice. Career Development International, 14, $204-$ 220. doi:10.1108/13620430910966406

Schutte, N., Toppinen, S., Kalimo, R. \& Schaufeli, W. B. (2000). The factorial validity of the Maslach Burnout Inventory - General Survey (MBI-GS) across occupational groups and nations. Journal of 
Occupational and Organizational Psychology, 73, 53-66. doi: 10.1348/096317900166877

Shirom, A, \& Ezrachi, Y. (2003). On the discriminant validity of burnout, depression and anxiety: A re-examination of burnout measure. Anxiety, Stress \& Coping: An International Journal, 16, 83-97. doi: 10.1080/1061580021000057059

Shirom, A. (2005). Reflections on the study of burnout. Work \& Stress, 19, 263-270. doi: 10.1080/02678370500376649

Taris, T. W., Schaufeli, W. B, De Boer, E. M., Schreurs, P. J. G. \& Caljé, D. G. (2000). On billijkheid in de arbeidssituatie, gezondheidenziekteverzuim. Hoe ziek is de calculerendeleraar? [Inequity at work, health and absenteeism. How ill is the calculative teacher?] Gedrag \& Gezondheid, 28, 123-137.

Taris, T. W., Le Blanc, P., Schaufeli, W. B. \& Schreurs, P. J. G. (2005). Are there relationships between the dimensions of the Maslach Burnout Inventory? A review and two longitudinal tests. Work \& Stress, 19, 256-262. doi: 10.1080/02678370500270453

Weisberg, J., Sagie, A. (1999). Teachers' physical, mental, emotional burnout: impact on intention to quit. The Journal of Psychology, 133, 333-339. doi: 10.1080/00223989909599746

Winwood, P., \& Winefield, A. H. (2004). Comparing two measures of burnout among dentists in Australia. International Journal of Stress Management, 11, 282- 289. doi: 10.1037/1072-5245.11.3.282

Maria Platsidou is an Associate Professor of Lifespan Developmental Psychology at the University of Macedonia, Greece

Athena Daniilidou is a PhD Student at the University of Macedonia, Greece

Contact Address: Maria Platsidou: platsidou@uom.edu.gr Athena Daniilidou: adaniilidou@uom.edu.gr 